\title{
Motivational influences on word recognition: II. Affective coding
}

\author{
EVA DREIKURS FERGUSON \\ Southern Illinois University at Edwardsville, Edwardsville, Illinois
}

\begin{abstract}
The effects of motivation and affective word content on tachistoscopic recognition were assessed in two experiments. Even with arousal heightened by white noise and with the word exposure slowed (15 vs. $10 \mathrm{msec}$ ) per trial, the earlier finding (Ferguson, 1988) was replicated, that under parafoveal viewing hunger, compared to satiation, fails to have a significant effect. Hemispheric asymmetry in affective bias for pleasant and unpleasant words was not found. However, strong evidence was found for significant affective word coding at the lexical stage: for categories with comparable interletter and word frequencies, food words required fewer trials for word recognition, and negatively emotional words required the most trials. In contrast, the reaction times, which likely are more representative of postlexical processing, were fastest for animal words.
\end{abstract}

Previous work by Ferguson $(1983,1988)$ has revealed that hunger as an approach motivation facilitates word recognition, but only under foveal, not parafoveal, viewing. Moreover, in two of the foveal-viewing experiments, under separate motivation manipulations of hunger and anxiety, affective word content had a significant effect. When food words, animal words, and negatively emotional words were equated across affective categories for word frequency and interletter associations, food words were most easily recognized, whereas negatively emotional words were least readily recognized. No needrelevance effects were evident, and affective word content had a comparable and significant effect regardless of which type of motivation was examined. Affective word content had less effect with laterally presented stimuli, for both foveal and parafoveal viewing (Ferguson, 1988), possibly due to differential recognition difficulty of left and right off-center word presentation.

In the above studies, the stimuli were presented very rapidly (for $10 \mathrm{msec}$ ) and repeated until correct word recognition occurred. The task differs in crucial ways from lexical decisions and word-naming studies. This task is akin to the purchasing of information until no more information is needed for correct recognition. Each trial consists of a stimulus exposure that provides a small amount of information. The dependent variable consists of trials to word recognition rather than reaction time (RT), with the two measures yielding somewhat disparate effects. For example, under foveal viewing, hungry subjects required less information purchasing (fewer trials to correct recognition) than did satiated subjects, but the recognized words were not named faster (Ferguson, 1988).

Grateful acknowledgment is given to the Research and Projects Office, Southern Illinois University at Edwardsville, for continued support of this research. Requests for reprints should be sent to Eva Dreikurs Ferguson, Psychology Department, Southern Illinois University at Edwardsville, Box 1121, Edwardsville, IL 62026.
In following up the above research concerning motivational influences on word recognition, the present investigation additionally addresses itself to questions concerning affective word content. One question is whether affective word content provides a code for lexical processing (see Chiarello, 1988, on the differentiation of prelexical, lexical, and postlexical processes). If recognition difficulty for off-center parafoveal presentations were eased, in comparison with the method of the prior studies (Ferguson, 1988), would food words as opposed to negatively emotional words be recognized sooner, as had been found (Ferguson, 1983) under foveal and center viewing? A further question concerns hemispheric asymmetry, which has been reported for various emotional states and for perception of affectively positive and negative stimuli. Controversy exists regarding whether the left (Levy, 1983; Tucker, 1981) or the right (Davidson, 1984; Dimond \& Farrington, 1977) hemisphere is biased for negative emotion (the reverse bias existing for the opposite hemisphere). If affective word categories significantly alter word recognition, is that effect lateralized? This can be studied in terms of different amounts of requisite trials (information purchase), in terms of word ratings, and in terms of RTs for word naming. Finally, the present investigation is intended to explore possible reasons for the failure of parafoveal viewing to yield significant effects of motivation, since with foveal viewing in three investigations (Erwin \& Ferguson, 1979; Ferguson, 1983, 1988), hunger as an approach motivation was found to facilitate word recognition significantly.

Two interrelated parafoveal experiments were conducted. To assess information purchasing, words of the earlier parafoveal study (Ferguson, 1988) were presented for $15 \mathrm{msec}$ instead of $10 \mathrm{msec}$. The slower presentation rate was used to assess (1) whether affective categories would yield recognition effects with off-center parafoveal viewing as had been obtained with center foveal viewing, and (2) whether with a slower word presentation, the expected 
effects of hunger motivation would occur with parafoveal viewing. Possibly a stronger motivational arousal is required under parafoveal than foveal viewing, in order to yield a significant effect of motivation on word recognition. Thus, white noise, frequently used to heighten arousal (e.g., by Berlyne \& Lewis, 1963; Eysenck, 1975), was added to the hunger condition in Experiment 1. In Experiment 2 , subjects under hunger-without-noise received the information-purchasing condition and subsequently named and rated the same words under 120-msec exposure. These ratings were used to assess hemispheric asymmetry in affective bias, which would be evident if one visual field yielded more extreme ratings and wordnaming RTs for positively emotional words, with the opposite field yielding more extreme data for negatively emotional words.

\section{EXPERIMENTS 1 AND 2}

\section{Method}

Subjects. In Experiment 1, 10 men and 10 women undergraduate volunteers were randomly assigned either to refrain from eating for $12 \mathrm{~h}$ before testing or to eat a big meal within $1 \mathrm{~h}$ prior to testing. In Experiment 2, 5 men and 5 women volunteers were assigned to the hunger (not eating for $12 \mathrm{~h}$ ) condition, and no satiated (eating within $1 \mathrm{~h}$ ) condition was used. A preexperimental undergraduate psychology class gave pleasantness ratings for $\mathbf{4 8}$ three-letter words printed on a sheet of paper that contained the 12 words used in the tachistoscopic task of Experiments 1 and 2. These paper-and-pencil ratings were made under unspecified conditions of hunger and satiation.

Apparatus. A Gerbrands three-field tachistoscope, a Gerbrands Lamp Drive Circuit unit, and a Gerbrands Digital Integrated Circuit unit were used, as described more fully previously (Ferguson, 1988). A Gerbrands Logic unit controlled which of three fields was activated. A centralfixation X was visible before and after word exposure, "catch" trials were used to assure center fixation, and a voice microphone and clock counter provided measurement of vocal RTs. Luminosity was $3.83 \mathrm{~mL}$ in the three fields, which were lit throughout testing.

Procedure. The overall procedure followed that described previously (Ferguson, 1988), with two words repeated in random alternation to the left or right of center until correctly recognized on two consecutive presentations for the given word. When a word in one visual field was recognized to criterion (two consecutive correct recognitions), a new word appeared in that field, regardless of what occurred in the other field. A given field contained six words, two per category, with the visual angle of all words between $2.25^{\circ}$ and $4.25^{\circ}$ from center fixation.

The words were from List 1 in the previous research (Ferguson, 1988): food words (rye, gum, cob, pie), animal words (fox, ram, elk, cow), and negatively emotional words (sin, hag, pus, woe). For the informationpurchasing task, words were presented for $15 \mathrm{msec}$. Overall, the previous parafoveal procedure was used. No corrective feedback occurred until the subject named a word for two consecutive presentations, and after 29 presentations the word exposure was systematically increased. To minimize problems of exposure duration, and to permit comparison with data from prior studies (Erwin \& Ferguson, 1979; Ferguson, 1983, 1988), data from the present studies are presented as trials to first correct recognition and not as trials to criterion.

In Experiment 1, the satiated subjects were tested as in previous research. However, the hungry subjects received white noise to heighten arousal. They received the usual practice trials without earphones, but prior to the test trials they received earphones with explanations about white noise. These subjects wore Grason-Stadler Telephonics TDH-39 " 300 " headphones, with $90 \mathrm{~dB}$ SPL white noise presented constantly and binaurally throughout the test trials by means of an Argonne 1431 white-noise generator. In Experiment 2, the hungry subjects were tested as the satiated subjects in Experiment 1 had been, without white noise or earphones, thus replicating the procedure of the prior parafoveal study (Ferguson, 1988) apart from the longer $(15-\mathrm{msec})$ word exposure. Comparison of hunger without noise and hunger with noise thus permitted assessment of the role of heightened arousal.

In Experiment 2, immediately after completing the word-recognition task, the subjects were shown 12 words they had just seen, plus 12 new filler words not used for data analysis. The words were shown parafoveally, once in the right and once in the left field (RVF and LVF), in a randomized order for a 120-msec exposure, which was slow enough for easy recognition. The subjects first said the word aloud, which provided the word-naming RT; then they gave a pleasantness rating on a scale from 1 (most unpleasant) to 7 (most pleasant), following the rating procedure of Broadbent and Gregory (1967). The parafoveal condition was compared with ratings from the preexperimental (paper-and-pencil), foveally viewed condition.

\section{RESULTS AND DISCUSSION}

As can be seen in Table 1, even with longer word exposure and with white-noise arousal induction, hunger motivation failed to yield a significant effect on the number of trials required for correct word recognition. The results thus replicate the earlier parafoveal data (Ferguson, 1988), and lead to the puzzling conclusion that in contrast to the foveal processing of words, parafoveal processing is not affected by the approach motivation of hunger. A $3 \times 2 \times 2$ ANOVA on trials for first correct word recognition, which compared hunger-with-noise and hungerwithout-noise, revealed no significant effect for noise but a significant effect for visual fields $(p=.05)$ and for category $(p<.001)$. None of the interactions were significant. When mean number of trials to first correct word recognition were compared for satiated subjects, a $3 \times 2 \times 2$ ANOVA comparing satiation and hunger-with-noise revealed only category to be significant $[F(2,36)=10.37$, $p<.001]$, and another $3 \times 2 \times 2$ ANOVA comparing satiation and hunger-without-noise revealed visual fields to be marginally significant $[F(1,18)=4.08, p=.058]$ and category to be significant $(p<.001)$. No interactions were significant. In both comparisons of hunger and satiation, motivation did not have a significant effect or interaction. Thus, even with increasing stimulus exposure duration and level of arousal, induced by white noise, hunger motivation failed to have a significant effect under parafoveal viewing.

Performance improved with the longer word exposure. Overall, fewer trials for first correct word recognition were required with the 15-msec exposure. Moreover, moderate visual field differences were obtained, with the predicted RVF advantage. Although the use of three-letter

Table 1

Mean Presentation to First Correct Word Recognition

\begin{tabular}{|c|c|c|c|c|c|c|}
\hline & \multicolumn{2}{|c|}{$\begin{array}{c}\text { Hungry, } \\
\text { White Noise }\end{array}$} & \multicolumn{2}{|c|}{$\begin{array}{l}\text { Hungry, } \\
\text { No Noise }\end{array}$} & \multicolumn{2}{|c|}{$\begin{array}{r}\text { Satiated, } \\
\text { No Noise }\end{array}$} \\
\hline & $\overline{\text { LVF }}$ & RVF & LVF & RVF & LVF & RVF \\
\hline Food & 2.60 & 3.80 & 6.95 & 7.85 & 3.20 & 5.30 \\
\hline Animal & 5.65 & 2.50 & 9.15 & 7.20 & 7.85 & 3.35 \\
\hline Neg. emot. & 9.20 & 7.70 & 14.85 & 7.80 & 10.05 & 7.95 \\
\hline
\end{tabular}

Note-Neg. emot. = negatively emotional words. LVF and RVF = left and right visual fields, respectively. 
Table 2

Mean Reaction Times (RTs) for Word Identification on First Correct Recognition

\begin{tabular}{|c|c|c|c|c|c|c|}
\hline & \multicolumn{2}{|c|}{$\begin{array}{c}\text { Hungry, } \\
\text { White Noise }\end{array}$} & \multicolumn{2}{|c|}{$\begin{array}{l}\text { Hungry, } \\
\text { No Noise }\end{array}$} & \multicolumn{2}{|c|}{$\begin{array}{l}\text { Satiated, } \\
\text { No Noise }\end{array}$} \\
\hline & LVF & RVF & LVF & RVF & LVF & RVF \\
\hline Food & $1,432.80$ & $1,671.20$ & $1,362.90$ & $1,630.90$ & $1,101.25$ & $1,100.60$ \\
\hline Animal & $1,394.75$ & $1,105.80$ & $1,372.35$ & $1,374.60$ & $1,188.85$ & $1,137.15$ \\
\hline Neg. emot. & $1,219.35$ & $1,776.40$ & $1,576.85$ & $1,571.35$ & $1,443.50$ & $1,361.15$ \\
\hline
\end{tabular}

Note-RTs are in msec. Neg emot. = negatively emotional words. LVF and RVF = left and right visual fields, respectively.

words may not reveal the superiority of the left cerebral hemisphere for the processing of words (Young \& Ellis, 1985), the present 15-msec word exposure overall did reveal a superior RVF processing of words. Importantly, the longer word exposure yielded clear-cut category effects, with food words requiring consistently fewer trials and negatively emotional words many more trials for first correct word recognition. These results confirm the previous findings with foveal-center viewing (Ferguson, 1983), and they indicate the strong impact of affective word content on lexical processing. It is proposed here that, as small components of word information are encoded, affective cues that are associated with these components provide differential aids in accessing the lexicon.

Table 2 shows that RTs for food words were not consistently faster, nor were negatively emotional words consistently slower. The $3 \times 2 \times 2$ ANOVAs, comparable to those performed on the data on Table 1 , did reveal significant category effects. However, these $F$ values were far smaller than those for the Table 1 data, and animal words rather than food words yielded the fastest RTs for two of the three groups of subjects.

The ratings of the preexperimental subjects and the hungry subjects of Experiment 2 support the fact that food words and animal words were judged as pleasant and negatively emotional words were judged as unpleasant. Ratings for the 12 test words by the preexperimental subjects, with 7 as maximally pleasant and 1 as maximally unpleasant, gave a mean of 4.82 for the food words, 3.92 for the animal words, and 2.05 for the negatively emotional words. Ratings for the subjects in Experiment 2, and RTs for their word naming, are presented in Table 3. Preexperimental mean ratings correlated $r=+.92$ with the 12 test words presented in Experiment 2 in RVF, and correlated $r=+.89$ with the 12 test words presented in LVF. As can be seen in Table 3, the parafoveally

Table 3

Mean Ratings and Mean RTs for Word Naming in Experiment 2

\begin{tabular}{lllllc}
\hline & \multicolumn{2}{c}{ Mean Ratings } & & \multicolumn{2}{c}{ Mean RTs for Naming } \\
\cline { 2 - 3 } \cline { 5 - 6 } & LVF & RVF & & LVF & RVF \\
\hline Food & 5.10 & 5.06 & & $1,226.10$ & $1,099.78$ \\
Animal & 5.10 & 5.11 & & $1,191.02$ & $1,031.38$ \\
Neg. emot. & 2.33 & 2.22 & & $1,268.65$ & $1,235.05$ \\
\hline
\end{tabular}

Note-For ratings, 7 is Pleasant and 1 is Unpleasant. Neg. emot. = negatively emotional words. LVF and RVF = left and right visual fields, respectively. presented words gave high pleasantness ratings for food words and animal words and low (unpleasant) ratings for negatively emotional words. No affective bias in terms of hemispheric asymmetry was evident. A $3 \times 2 \times 2$ ANOVA showed category $(p<.001)$, but not visual field, to be significant for the pleasantness ratings. The word-naming latencies also revealed no affective asymmetry. The $3 \times 2$ ANOVA for RTs revealed a significant effect for category $[F(2,18)=3.78, p=.042]$ and a marginally significant effect for visual field $(p=.076)$. As with the RT data in Table 2, RTs of word naming on the rating task were fastest for the animal words. The hypothesis of asymmetry in affective bias would predict a significant category $x$ visual field interaction, but none was obtained. No support was found either for the left hemisphere to be biased for positive affect and the right hemisphere to be biased for negative affect, or for the opposite type of affective bias.

In summary, the present investigation supports the concept of affective word coding at the lexical processing stage, but it lends no support to the concept of an asymmetric affective bias for the two hemispheres. Studies of such an affective bias with normal (rather than clinical) subjects have ordinarily been conducted with nonverbal stimuli, such as tones, cartoon films, or pictures of faces. It may be that when the stimuli are words, the hemispheres reveal a different type of affective processing. This question remains unresolved and needs further exploration. It is also not clear why hunger motivation failed to facilitate word recognition under parafoveal viewing even when other variables, such as affective word content, proved to be significant with the longer stimulus exposures in the present investigation. The failure to find a motivational effect under parafoveal viewing could be due to one hemisphere's, rather than two, initially processing the stimulus. Alternatively, the parafoveal processing of words may be different in some important ways from foveal processing. Other explanations are possible as well. In further studies, these issues are currently being explored.

\section{REFERENCES}

BERLYNE, D. E., \& LEWIS, J. L. (1963). Effects of heightened arousal on human exploratory behavior. Canadian Journal of Psychology, 17, 398-410.

Broadbent, D. E., \& Gregory, M. (1967). Perception of emotionally toned words. Nature, 216, 581-584.

Chiarello, C. (1988). Lateralization of lexical processes in the normal brain: A review of visual half-field research. In H. A. Whitaker (Ed.), 
Contemporary reviews in neuropsychology (pp. 36-76). New York: Springer-Verlag.

DAVIDSON, R. J. (1984). Hemispheric asymmetry and emotion. In K. R. Scherer \& P. Ekman (Eds.), Approaches to emotion (pp. 39-57). Hillsdale, NJ: Erlbaum.

Dimond, S., \& FarRington, L. (1977). Emotional response to films shown to the right or left hemisphere of the brain measured by heart rate. Acta Psychologica, 41, 255-260.

Erwin, R. J., \& Ferguson, E. D. (1979). The effect of food and water deprivation and satiation on recognition. American Journal of Psychology, 92, 611-626.

EYSENCK, M. W. (1975). Effects of noise, activation level, and response dominance on retrieval from semantic memory. Journal of Experimental Psychology: Human Learning \& Memory, 104, 143-148.

Ferguson, E. D. (1983). The effect of motivation and word characteristics on recognition. American Journal of Psychology, 96, 253-266.
FERGUSON, E. D. (1988). Motivational influences on word recognition: I. Foveal and parafoveal viewing. Bulletin of the Psychonomic Society, 26, 203-205.

LEVY, J. (1983). Individual differences in cerebral hemisphere asymmetry: Theoretical issues and experimental considerations. In J. B. Hellige (Ed.), Cerebral hemisphere asymmetry: Method, theory, and application (pp. 465-497). New York: Praeger.

TUCKER, D. M. (1981). Lateral brain function, emotion, and conceptualization. Psychological Bulletin, 89, 19-46.

Young, A. W., \& Elus, A. W. (1985). Different methods of lexical access for words presented in the left and right visual hemifields. Brain \& Language, 24, 326-358.

(Manuscript received December 2, 1988.) 